\title{
Pentadecapeptide BPC157 reduces bleeding and thrombocytopenia after amputation in rats treated with heparin, warfarin, L-NAME and L-arginine
}

\author{
Predrag Sikirić*, Mirjana Stupnišek, Antonio Kokot, Domagoj Drmić, Maša Hrelec Patrlj, \\ Anita Zenko Sever, Božo Radić, Davor Bojić, Aleksandar Včev, Sven Seiwerth \\ University of Zagreb School of Medicine, Zagreb, Croatia
}

Rationale: BPC 157 is a stable gastric pentadecapeptide recently implicated with a role in hemostasis. While NO is largely implicated in hemostatic mechanisms, in tail-amputation-models under heparin- and warfarin-administration, both the NO-synthase (NOS)-blocker, L-NAME (prothrombotic) and the NOS-substrate L-arginine (antithrombotic) have been little investigated.

Objective: To investigate the effects of BPC 157 after LNAME and/or L-arginine administration. Namely, bleeding/thrombocytopenia (even with anticoagulant administration) after tail-amputation and thrombosis of the abdominal aorta anastomotic site, were both counteracted. BPC 157 also particularly modulates the NO-system and wound-healing, including that of blood vessels.

Methods and Results: Tail amputation, and/or i.v.-heparin (10 mg/kg), i.g.-warfarin (1.5 mg/kg/day for 3 days) were used in rats. Medication includes BPC 157, L-NAME, L-argi-

\section{Received: $24^{\text {th }}$ Apr 2014}

*Address for correspondence: Zavod za farmakologiju Medicinskog fakulteta Sveučilišta u Zagrebu, Šalata 11, HR-10000 Zagreb, Croatia.

Phone: +385-1-4566-833

E-mail: sikiric@mef.hr nine, alone and/or together applied accordingly. After (tail) amputation, with or without i.v.-heparin or i.g.-warfarin, BPC 157 (10 $\mu \mathrm{g} / \mathrm{kg}, 10 \mathrm{ng} / \mathrm{kg}$, i.p., i.v. (heparin), i.g. (warfarin)) always reduced bleeding time and/or haemorrhage and counteracted thrombocytopenia. As for L-NAME and/or L-arginine, we noted: L-arginine (100 mg/kg i.p.)-rats: more bleeding, less/no thrombocytopenia; L-NAME (5 mg/kg i.p.)-rats: less bleeding (amputation only), but present thrombocytopenia; L-NAME+L-arginine-rats also exhibited thrombocytopenia: L-NAME counteracted L-arginine-increased bleeding, Larginine did not counteract L-NAME-thrombocytopenia. All of the animals receiving BPC 157 in addition (BPC 157 $\mu \mathrm{g}+\mathrm{L}-$ NAME; BPC $157 \mu \mathrm{g}+\mathrm{L}$-arginine, BPC $157 \mu \mathrm{g}+\mathrm{L}-\mathrm{NAME}+\mathrm{L}-$ arginine), exhibited decreased haemorrhage and markedly counteracted thrombocytopenia.

Conclusions: L-NAME (thrombocytopenia), L-arginine (increased haemorrhage) counteraction and BPC 157 (decreased haemorrhage, counteracted thrombocytopenia) with rescue against two different anticoagulants, implicate a BPC 157 modulatory and balancing role with rescued NO-hemostatic mechanisms.

KEYWORDS: BPC 157, thrombocytopenia, bleeding, NO system, rats.

CITATION: Cardiol Croat. 2014;9(5-6):257.

\section{Literature}

1. Stupnisek M, Franjic S, Drmic D, et al. Pentadecapeptide BPC 157 reduces bleeding time and thrombocytopenia after amputation in rats treated with heparin, warfarin or aspirin. Thromb Res. 2012;129(5):652-9.

2. Sikiric P, Seiwerth S, Rucman R, et al. Stable gastric pentadecapeptide BPC 157-NO-system relation. Curr Pharm Des. 2014;20(7):1126-35. 